\title{
Decreased expression of serum semaphorin 3B is associated with poor prognosis of patients with hepatocellular carcinoma
}

\author{
GUANG-ZHEN LI ${ }^{1}$, DI SHEN ${ }^{2}$, GUANG-HONG LI $^{3}$, MENG WEI $^{1}$, LI-JIE ZHENG ${ }^{4}$, ZENG-LI LIU $^{1}$, \\ RONG-QI SUN ${ }^{1}$, SHAO-JUN ZHOU ${ }^{4}$, ZONG-LI ZHANG $^{1}$ and YAN-CHAO GAO ${ }^{5}$ \\ ${ }^{1}$ Department of General Surgery, Qilu Hospital of Shandong University, Jinan, Shandong 250012; \\ ${ }^{2}$ Department of Gynecology and Obstetrics, Shandong Maternity and Child Care Hospital, Jinan, \\ Shandong 250014; ${ }^{3}$ Department of Endocrinology, The Affiliated Hospital of Taishan Medical College, \\ Tai'an, Shandong 271000; ${ }^{4}$ Department of General Surgery, Qilu Hospital of Shandong University, \\ Qingdao, Shandong 266035; ${ }^{5}$ Department of Hepatobiliary Surgery, \\ Liaocheng People's Hospital, Liaocheng, Shandong 252000, P.R. China
}

Received January 19, 2020; Accepted December 8, 2020

DOI: $10.3892 / \mathrm{etm} .2021 .9667$

\begin{abstract}
Semaphorin 3B (SEMA-3B), which belongs to the semaphorin family, has an important role in cell apoptosis and inhibition of angiogenesis. A previous study by our group revealed that SEMA-3B was downregulated in tumor tissues of patients with hepatocellular carcinoma (HCC) and exerts anti-motility and anti-invasion effects on tumor cells. However, the serum levels of SEMA-3B and their clinical significance have remained elusive; therefore, the aim of the present study was to monitor its expression in HCC and investigate its clinical significance. ELISA was used to determine the serum levels of SEMA-3B in 132 patients with HCC and 57 healthy individuals. The association between SEMA-3B and clinicopathological parameters was investigated. Serum SEMA-3B was indicated to be significantly decreased in patients with HCC as compared with that in the controls $(\mathrm{P}<0.05)$ and it was negatively associated with tumor size $(\mathrm{P}=0.039)$, encapsulation $(\mathrm{P}=0.002)$ and $\mathrm{TNM}$ stage $(\mathrm{P}=0.034)$. The prognosis of patients with low expression of SEMA-3B was poor. In conclusion, the results of the present study revealed that serum SEMA-3B is decreased in HCC and is negatively associated with prognosis; therefore, it may be used as a prognostic marker in HCC.
\end{abstract}

Correspondence to: Professor Zong-Li Zhang, Department of General Surgery, Qilu Hospital of Shandong University, 107 Wenhua West Road, Jinan, Shandong 250012, P.R. China

E-mail: 13708933969@163.com

Professor Yan-Chao Gao, Department of Hepatobiliary Surgery, Liaocheng People's Hospital, 67 Dongchang West Road, Liaocheng, Shandong 252000, P.R. China

E-mail: lcyygyc@126.com

Key words: hepatocellular carcinoma, semaphorin 3B, serum, prognosis

\section{Introduction}

Hepatocellular carcinoma (HCC) is one of the most common malignant tumor types and is responsible for $\sim 700,000$ deaths annually worldwide (1). With the advances in diagnostic and therapeutic methods, the prognosis of liver cancer has improved, but the frequent recurrence and high metastasis rates of HCC adversely affect patient outcomes. Therefore, the identification of tumor markers is crucial for early diagnosis, treatment and outcome prediction in HCC.

Semaphorin 3B (SEMA-3B), which belongs to the semaphorin family, is a secreted molecule that contains a highly conserved Sema domain in the amino terminus. SEMA-3B was initially discovered as an inhibitory axonal guidance molecule, but recent studies revealed that SEMA-3B also functions as a tumor suppressor in lung, renal, gastric, breast and prostate cancers (2-7). SEMA-3B forms a complex with neuropilins (NPs) and plexins on the cell surface. Vascular endothelial growth factor (VEGF)-A also binds to NPs and this complex promotes cellular migration and promotes tumor growth (4,8-10). SEMA-3B family proteins may competitively inhibit the function of VEGF in promoting tumor angiogenesis, as they share the same transmembrane receptors for NP-1 and NP-2 (4). SEMA-3B inhibits the migration and proliferation of cancer cells; therefore, it was hypothesized that its expression levels may affect the prognosis of patients with HCC. A previous study by our group demonstrated the suppressive effect of the SEMA-3B protein on the migration and invasion ability of cancer cells in vitro (11).

Aberrant expression and methylation of SEMA-3B may be of value as a marker in patients with lung and renal cancer (12). The previous study by our group revealed that SEMA-3B is downregulated in tumor tissues and has a tumor suppressor role in HCC (11). The aim of the present study was to examine the clinical value of serum SEMA-3B as a tumor marker and determine whether it may be used as a prognostic marker. 


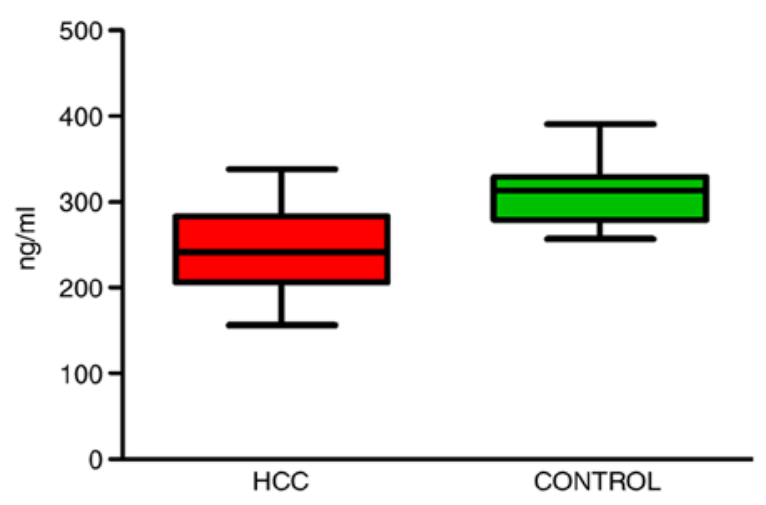

Figure 1. Serum levels of SEMA-3B are downregulated in HCC. The serum concentration of SEMA-3B was determined with ELISA in patients with $\mathrm{HCC}$ and healthy subjects as the control group. There was a significant difference in serum SEMA-3B between the two groups $(\mathrm{t}=10.48, \mathrm{P}<0.0001)$. The serum levels of SEMA-3B were significantly downregulated in patients with HCC compared with those in the healthy controls $(242.7 \pm 3.8444 .06$ vs. $310.7 \pm 4.3232 .62 \mathrm{ng} / \mathrm{ml}$, respectively; $\mathrm{P}<0.05$ ). SEMA-3B, semaphorin $3 \mathrm{~B}$; $\mathrm{HCC}$, hepatocellular carcinoma.

\section{Materials and methods}

Sample collection. A total of 132 patients (73 males and 59 females, aged 37-78 years) with HCC who underwent curative surgery and were diagnosed pathologically were hospitalized at the Department of General Surgery of Qilu Hospital, Shandong University (Jinan, China) between May 2013 and December 2014, and all cases who presented during this period were enrolled. Serum samples were also collected during this period from 57 subjects who had no liver disease (healthy controls; 31 males and 26 females, aged 42-80 years). All subjects and their families agreed to participate in the present study and signed informed consent. The protocol was approved by the Ethics Committee of Qilu Hospital (Jinan, China). All patients who had a visit were contacted by telephone every month and had ultrasound or CT scan every 2-3 months. The follow-up was terminated in November 2019.

ELISA. Peripheral blood $(5 \mathrm{ml})$ was collected from each of the subjects, centrifuged at $3000 \mathrm{x}$ g for $15 \mathrm{~min}$ at $4^{\circ} \mathrm{C}$ and the serum was separated and stored in the refrigerator at $-80^{\circ} \mathrm{C}$ until use. The serum SEMA-3B was examined by ELISA (DLdevelop; cat. no. DL-SEMA3B-Hu) according to the manufacturer's protocol.

Statistical analysis. For statistical comparison of count data between SEMA-3B expression and clinical indicators, the $\chi^{2}$ test was used. The levels of SEMA-3B between patients with HCC and controls were compared using Student's t-test. Survival curves were constructed using the Kaplan-Meier survival analysis method and the differences in survival curves were compared with the log-rank test. All the statistical analyses were performed with SPSS 18.0 statistical software (SPSS Inc.) and $\mathrm{P}<0.05$ was considered to indicate a statistically significant difference.

\section{Results}

Serum SEMA-3B is downregulated in HCC. The expression of SEMA-3B in the serum of patients with HCC and healthy
Table I. Clinicopathological variables associated with different expression patterns of serum SEMA-3B.

\begin{tabular}{|c|c|c|c|}
\hline \multirow[b]{2}{*}{ Variable } & \multicolumn{2}{|c|}{ Number of patients } & \multirow[b]{2}{*}{ P-value } \\
\hline & High & Low & \\
\hline Sex & & & 0.382 \\
\hline Male & 33 & 40 & \\
\hline Female & 32 & 27 & \\
\hline Age (years) & & & 0.229 \\
\hline$\leq 60$ & 28 & 36 & \\
\hline$>60$ & 37 & 31 & \\
\hline HBsAg status & & & 0.374 \\
\hline Negative & 22 & 28 & \\
\hline Positive & 43 & 39 & \\
\hline $\mathrm{AFP}(\mathrm{ng} / \mathrm{ml})$ & & & 0.163 \\
\hline$\leq 20$ & 30 & 25 & \\
\hline$>20$ & 35 & 42 & \\
\hline Liver cirrhosis & & & 0.209 \\
\hline Negative & 20 & 28 & \\
\hline Positive & 45 & 39 & \\
\hline Cell differentiation & & & 0.475 \\
\hline Moderate/poor & 43 & 40 & \\
\hline High & 22 & 27 & \\
\hline Number of tumors & & & 0.008 \\
\hline Solitary & 41 & 25 & \\
\hline Multiple & 24 & 40 & \\
\hline Largest tumor size $(\mathrm{cm})$ & & & 0.039 \\
\hline$\leq 5$ & 39 & 28 & \\
\hline$>5$ & 26 & 40 & \\
\hline Tumor capsule & & & 0.002 \\
\hline Absent & 40 & 22 & \\
\hline Present & 25 & 45 & \\
\hline CLIP score (points) & & & 0.025 \\
\hline $0-1$ & 41 & 29 & \\
\hline$\geq 2$ & 24 & 38 & \\
\hline TNM stage & & & 0.034 \\
\hline I & 36 & 23 & \\
\hline II/III & 29 & 42 & \\
\hline
\end{tabular}

SEMA-3B, semaphorin 3B; HCC, hepatocellular carcinoma; HBsAg, hepatitis B surface antigen; AFP, $\alpha$-fetoprotein; CLIP, Cancerof the Liver Italian Program.

controls was measured to determine whether there was any difference between the two groups. ELISA was used to monitor the expression of serum SEMA-3B. The serum levels of SEMA-3B were indicated to be significantly downregulated in patients with $\mathrm{HCC}$ compared with those in the controls (242.7 \pm 44.06 vs. $310.7 \pm 32.62$ ng/ml, respectively; P<0.05; Fig. 1). expression patterns of serum SEMA-3B. HCC cases were 
A

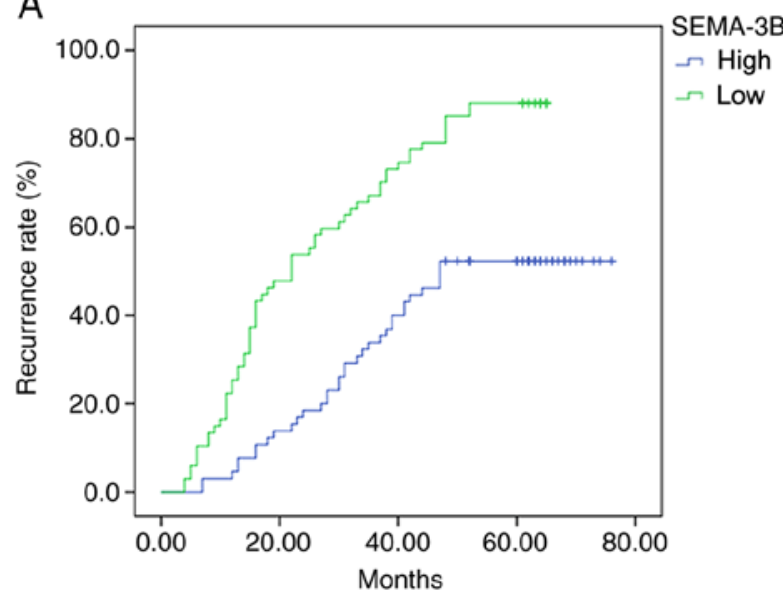

B

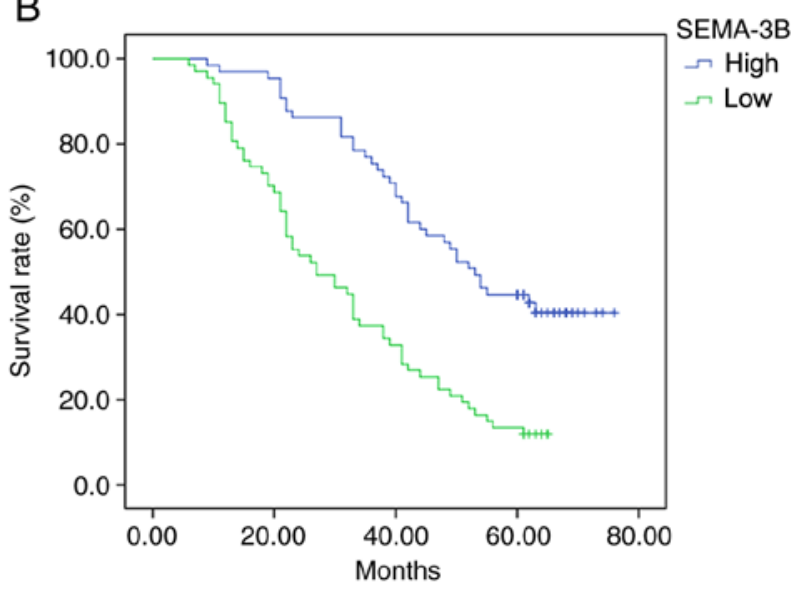

Figure 2. Prognostic significance of SEMA-3B in HCC. (A) The recurrence rate in the low group was significantly lower than that in the high group (P<0.001) and $(\mathrm{B})$ the survival rate in the high group was significantly higher than that in the low group $(\mathrm{P}<0.001)$. For patients who were alive and did not relapse at the last follow-up, they are treated as censored data during the statistical analysis. SEMA-3B, semaphorin 3B; HCC, hepatocellular carcinoma.

divided into two groups according to the mean expression of serum SEMA-3B (cut-off, $242.7 \mathrm{ng} / \mathrm{ml}$ ). The expression of serum SEMA-3B was high in 65 and low in $67 \mathrm{HCC}$ patients. Serum SEMA-3B was negatively associated with the number of tumors, largest tumor size, presence of tumor capsule, Cancer of the Liver Italian Program (CLIP) score (13) and the TNM stage $(\mathrm{P}<0.05$; Table I).

Serum SEMA-3B may be used as a prognostic marker for $H C C$. Clinical follow-up of the patients revealed that the cancer recurrence rate in the low-expression group was significantly lower compared with that in the high-expression group ( $\mathrm{P}<0.001$; Fig. 2A). The recurrence rates of the high-expression group at 1,3 and 5 years were $4.62,29.23$ and $60.00 \%$, respectively. The recurrence rates of the low-expression groups were $25.37,67.16$ and $88.06 \%$, respectively. Furthermore, the survival rate in the high-expression group was significantly higher compared with that in the low-expression group ( $\mathrm{P}<0.001$; Fig. 2B): 1-year survival rate 96.92 vs. $83.58 \%$, respectively; 3-year survival rate 72.308 vs. $53.73 \%$, respectively; and 5-year survival rate 38.46 vs. $31.34 \%$, respectively.

\section{Discussion}

As HCC is characterized by low sensitivity to radiotherapy and chemotherapy, the prognosis of the patients with $\mathrm{HCC}$ is poor (14). Despite advances in the development of early detection methodologies, the questionable effectiveness and high cost of the procedures available for the treatment of HCC pose a challenge for disease management. Therefore, it is crucial to identify novel therapeutic targets and diagnostic biomarkers to ensure timely treatment and improve survival rates. In the present study, the clinical value of serum SEMA-3B was assessed and it was discussed whether it may be of value in the treatment of HCC.

SEMA-3B, encoded at chromosome $3 \mathrm{p} 21.3$, is a secreted molecule that contains a highly conserved Sema domain in the amino terminus. SEMA-3B was initially discovered as an inhibitory axonal guidance molecule and it was also recently recognized as a candidate tumor suppressor gene (15-17). Loss of SEMA-3B expression in cells of the tumor microenvironment, as well as tumor cells themselves, may increase the aggressiveness of breast cancer (7). In a previous study by our group, the expression of SEMA-3B protein was investigated in HCC and normal tissues and the expression of SEMA-3B was indicated to be significantly downregulated in $\mathrm{HCC}$ tissues (11). To the best of our knowledge, no previous studies have reported the serum levels of SEMA-3B and SEMA-3F in patients with $\mathrm{HCC}$ to date; therefore, ELISA was used to monitor the expression of serum SEMA-3B and SEMA-3F, but only the expression of serum SEMA-3B was observed to be decreased compared with that in healthy controls. Several mechanisms are involved in decreasing the expression of SEMA-3B. Methylation participates in the downregulation of SEMA-3B (18). Introduction of exogenous p53 into a glioblastoma cell line lacking wild-type p53, U373MG, markedly induced the expression of SEMA-3B mRNA, as SEMA-3B is a direct target of p53 (19).

Based on the expression of serum SEMA-3B in patients with $\mathrm{HCC}$, the patients were followed-up. A $\chi^{2}$ test for the association of clinicopathological parameters with the serum levels of SEMA-3B (high vs. low) revealed that the expression levels of SEMA-3B were significantly associated with the formation of a capsule, possibly via the inhibitory effect of SEMA-3B on the formation of vessels (20). SEMA-3B is able to inhibit the expression and activity of MMP-2 and MMP-9 (21,22). SEMA-3B family proteins may competitively inhibit the function of VEGF in promoting tumor angiogenesis, as they share the same transmembrane receptors of NP-1 and NP-2 (4). The expression of NP-1 was reported to be associated with the clinicopathologic parameters of patients with cholangiocarcinoma (23). The positive rates of NP-1 in HCC tissues and adjacent tissues were 63.0 and $4.1 \%$, and a study by our group also indicated that the expression of NP-1 in HCC is associated with clinicopathological parameters (24). The previous study (11) by our group demonstrated a negative association between the level of SEMA-3B protein expression and microvascular density, which may reflect the fact that SEMA-3B has an important role in angiogenesis. In addition, serum SEMA-3B was indicated to be negatively correlated with the number of tumors, largest tumor size, tumor 
capsule, CLIP score and TNM stage in the present study. As the number of tumors, largest tumor size, tumor capsule, CLIP score and TNM stage are closely associated with the prognosis of the patients (25), it was inferred that serum SEMA-3B is a tumor suppressor gene.

In order to determine the possible influence of the serum levels of SEMA-3B on prognosis, patients were divided into two groups, namely a high- and a low-expression group. Analysis of the follow-up data of the patients of the present study revealed that the recurrence rate in the high-expression group was markedly lower compared with that in the low-expression group, while the cumulative survival rate was significantly higher compared with that of the low-expression group. Suppression of miR-221 was previously reported to inhibit glioma cells by targeting SEMA-3B, and SEMA-3B inhibited cell proliferation and invasion (26). SEMA-3B was also indicated to be associated with a favorable survival prognosis for patients with esophageal squamous cell carcinoma due to upregulating p53 and p21 (27). A previous study by our group confirmed that SEMA-3B inhibits angiogenesis and cell migration, and SEMA-3B levels in HCC tissue may be used as a marker to predict prognosis (11). Therefore, serum SEMA-3B may be a valuable indicator for predicting the prognosis of patients with HCC.

In conclusion, serum SEMA-3B may be easily detected in the peripheral blood and may be used for the diagnosis and prediction of prognosis of patients with HCC. The exact role of SEMA-3B in cancer development and underlying mechanisms of action require further elucidation, but the results of the present study indicated the potentially important role of serum SEMA-3B in the diagnosis and prediction of prognosis of patients with HCC.

\section{Acknowledgements}

Not applicable.

\section{Funding}

This study was supported by Shandong Provincial Natural Science Foundation of China (grantno. Z R2020QH203and 26010105201516).

\section{Availability of data and materials}

The datasets used and/or analyzed during the current study are available from the corresponding author on reasonable request.

\section{Authors' contributions}

ZLZ and YCG conceived the study and drafted the manuscript. GZL enrolled subjects and compared their data. DS, GHL, MW, LJZ, ZLL, RQS and SJZ performed ELISA and collected data. All authors read and approved the final manuscript. ZLZ and YCG confirmed the authenticity of the raw data.

\section{Ethics approval and consent to participate}

This study was approved by the ethics committee of Qilu Hospital (Jinan, China). Patients who participated in this study, provided written informed consent and had complete clinical data.

\section{Patient consent for publication}

Not applicable.

\section{Competing interests}

The authors declare that they have no competing interests.

\section{References}

1. Jemal A, Bray F, Center MM, Ferlay J, Ward E and Forman D: Global cancer statistics. CA Cancer J Clin 61: 69-90, 2011.

2. Sekido Y, Bader S, Latif F, Chen JY, Duh FM, Wei MH, Albanesi JP, Lee CC, Lerman MI and Minna JD: Human semaphorins $\mathrm{A}(\mathrm{V})$ and IV reside in the 3 p21.3 small cell lung cancer deletion region and demonstrate distinct expression patterns. Proc Natl Acad Sci USA 93: 4120-4125, 1996.

3. Tse C, Xiang RH, Bracht T and Naylor SL: Human Semaphorin 3B (SEMA3B) located at chromosome 3p21.3 suppresses tumor formation in an adenocarcinoma cell line. Cancer Res 62: 542-546, 2002

4. Castro-Rivera E, Ran S, Thorpe P and Minna JD: Semaphorin 3B (SEMA3B) induces apoptosis in lung and breast cancer, whereas VEGF165 antagonizes this effect. Proc Natl Acad Sci USA 101: 11432-11437, 2004.

5. Beuten J, Garcia D, Brand TC, He X, Balic I, Canby-Hagino E, Troyer DA, Baillargeon J, Hernandez J, Thompson IM, et al: Semaphorin $3 \mathrm{~B}$ and $3 \mathrm{~F}$ single nucleotide polymorphisms are associated with prostate cancer risk and poor prognosis. J Urol 182: 1614-1620, 2009.

6. Pignata A, Ducuing H and Castellani V: Commissural axon navigation: Control of midline crossing in the vertebrate spinal cord by the semaphorin 3B signaling. Cell Adhes Migr 10: 604-617, 2016.

7. Shahi P, Wang CY, Chou J, Hagerling C, Gonzalez Velozo H, Ruderisch A, Yu Y, Lai MD and Werb Z: GATA3 targets semaphorin 3B in mammary epithelial cells to suppress breast cancer progression and metastasis. Oncogene 36: 5567-5575, 2017.

8. Bernatchez PN, Rollin S, Soker S and Sirois MG: Relative effects of VEGF-A and VEGF-C on endothelial cell proliferation, migration and PAF synthesis: Role of neuropilin-1. J Cell Biochem 85: 629-639, 2002.

9. Castro-Rivera E, Ran S, Brekken RA and Minna JD: Semaphorin 3B inhibits the phosphatidylinositol 3-kinase/Akt pathway through neuropilin-1 in lung and breast cancer cells. Cancer Res 68: 8295-8303, 2008.

10. Sabag AD, Smolkin T, Mumblat Y, Ueffing M, Kessler O, Gloeckner CJ and Neufeld G: The role of the plexin-A2 receptor in Sema3A and Sema3B signal transduction. J Cell Sci 127: 5240-5252, 2014

11. Li G, Gao Y, Ma D and Zhang Z: Downgraded expression of SEMA3B indicates an unfavorable prognosis in patients of resectable hepatocellular carcinoma. Int J Clin Exp Pathol 9: 841-853, 2016.

12. Loginov VI, Dmitriev AA, Senchenko VN, Pronina IV, Khodyrev DS, Kudryavtseva AV, Krasnov GS, Gerashchenko GV, Chashchina LI, Kazubskaya TP, et al: Tumor Suppressor Function of the SEMA3B Gene in Human Lung and Renal Cancers. PLoS One 10: $\mathrm{e} 0123369,2015$.

13. Llovet JM and Bruix J: Prospective validation of the Cancer of the Liver Italian Program (CLIP) score: A new prognostic system for patients with cirrhosis and hepatocellular carcinoma. Hepatology 32: 679-680, 2000.

14. Lohitesh K, Chowdhury R and Mukherjee S: Resistance a major hindrance to chemotherapy in hepatocellular carcinoma: An insight. Cancer Cell Int 18: 44, 2018.

15. Braga EA, Kashuba VI, Maliukova AV, Loginov VI, Senchenko VN, Bazov IV, Kiselev LL and Zabarovskiü ER: New tumor suppressor genes in hot spots of human chromosome 3: New methods of identification. Mol Biol (Mosk) 37: 194-211, 2003 (In Russian).

16. Falk J, Bechara A, Fiore R, Nawabi H, Zhou H, Hoyo-Becerra C, Bozon M, Rougon G, Grumet M, Püschel AW, et al: Dual functional activity of semaphorin $3 \mathrm{~B}$ is required for positioning the anterior commissure. Neuron 48: 63-75, 2005. 
17. Tischoff I, Markwarth A, Witzigmann H, Uhlmann D, Hauss J, Mirmohammadsadegh A, Wittekind C, Hengge UR and Tannapfel A: Allele loss and epigenetic inactivation of 3p21.3 in malignant liver tumors. Int J Cancer 115: 684-689, 2005.

18. Chen R, Zhuge X, Huang Z, Lu D, Ye X, Chen C, Yu J and Lu G: Analysis of SEMA3B methylation and expression patterns in gastric cancer tissue and cell lines. Oncol Rep 31: 1211-1218, 2014.

19. Ochi K, Mori T, Toyama Y, Nakamura Y and Arakawa H: Identification of semaphorin3B as a direct target of $\mathrm{p} 53$. Neoplasia 4: 82-87, 2002.

20. Neufeld G, Lange T, Varshavsky A and Kessler O: Semaphorin signaling in vascular and tumor biology. Adv Exp Med Biol 600: $118-131,2007$.

21. Halbersztadt A, Haloń A, Pajak J, Robaczyński J, Rabczynski J and St Gabryś M: The role of matrix metalloproteinases in tumor invasion and metastasis. Ginekol Pol 77: 63-71, 2006 (In Polish).

22. Patel S, Sumitra G, Koner BC and Saxena A: Role of serum matrix metalloproteinase-2 and -9 to predict breast cancer progression. Clin Biochem 44: 869-872, 2011.

23. Zhu H, Zhai B, He C, Li Z, Gao H, Niu Z, Jiang X, Lu J and Sun X: LncRNA TTN-AS1 promotes the progression of cholangiocarcinoma via the miR-320a/neuropilin-1 axis. Cell Death Dis 11: 637, 2020 .
24. Gao Y: Expression of Semaphorin-3B, Vascular endothelial growth factor,and their common receptor Neuropilin-1 inHepatocellular carcinoma. China Doctoral Thesis Library 04, 2014.

25. Huang YH, Chen CH, Chang TT, Chen SC, Wang SY, Lee HS Lin PW, Huang GT, Sheu JC, Tsai HM, et al: Evaluation of predictive value of CLIP, Okuda, TNM and JIS staging systems for hepatocellular carcinoma patients undergoing surgery. J Gastroenterol Hepatol 20: 765-771, 2005.

26. Cai G, Qiao S and Chen K: Suppression of miR-221 inhibits glioma cells proliferation and invasion via targeting SEMA3B. Biol Res 48: 37, 2015.

27. Tang $\mathrm{H}$, Wu Y, Liu M, Qin Y, Wang H, Wang L, Li S, Zhu H, He Z, Luo J, et al: SEMA3B improves the survival of patients with esophageal squamous cell carcinoma by upregulating p53 and p21. Oncol Rep 36: 900-908, 2016.

(†) $\ominus$ This work is licensed under a Creative Commons Attribution-NonCommercial-NoDerivatives 4.0 International (CC BY-NC-ND 4.0) License. 